\title{
Increase in osteoclastogenesis in an obese Otsuka Long-Evans Tokushima fatty rat model
}

\author{
TOMOYO OOTSUKA $^{1}$, ATSUKO NAKANISHI ${ }^{1}$ and IKUYO TSUKAMOTO ${ }^{1,2}$ \\ ${ }^{1}$ Department of Food Science and Nutrition, Nara Women's University, Nara 630-8506; \\ ${ }^{2}$ Department of Clinical Nutrition, Hiroshima International University, Kure, Hiroshima 737-0112, Japan
}

Received June 14, 2014; Accepted March 3, 2015

DOI: $10.3892 / \mathrm{mmr} .2015 .3811$

\begin{abstract}
In the present study, the effects of obesity on bone metabolism were investigated using a hyperphagic and obese rat model, the Otsuka Long-Evans Tokushima fatty (OLETF) rat, which exhibits normal glycemic control at 8 weeks of age. Body weight, food intake, fat mass, markers of bone resorption, the activities of tartrate-resistant acid phosphatase (TRAP) and cathepsin K, the number of osteoclasts in the proximal tibia, and the serum C-terminal crosslinking telopeptide level were higher in OLETF rats than those in control rats (Long-Evans Tokushima Otsuka; LETO). However, no differences in markers of bone formation, alkaline phosphatase activity, the number of osteoblasts in the proximal tibia or the serum osteocalcin level were observed. mRNA and protein levels of c-fms, receptor for activation of nuclear factor- $\mathrm{\kappa} B$ (RANK), RANK ligand (RANKL), TRAP and cathepsin K were significantly increased in OLETF rats, although those levels of macrophage colony-stimulating factor (M-CSF) and osteoprotegerin (OPG) were similar to those in LETO rats. The level of serum tumor necrosis factor $\alpha(\mathrm{TNF} \alpha)$, and that of TNF $\alpha$ mRNA in bone, increased in association with the activation of NFKB. Furthermore, a frequency analysis and a colony formation assay respectively showed that the number of osteoclast precursors and the number of colony-forming cells induced by M-CSF each increased in OLETF rats compared
\end{abstract}

Correspondence to: Professor Ikuyo Tsukamoto, Department of Clinical Nutrition, Hiroshima International University, 5-1-1, Hirokoshingai, Kure, Hiroshima 737-0112, Japan

E-mail: itsuka@cc.nara-wu.ac.jp

Abbreviations: ALP, alkaline phosphatase; CTx, C-terminal crosslinking telopeptide; IL-6, interleukin-6; LETO, Long-Evans Tokushima Otsuka; M-CSF, macrophage colony-stimulating factor; MITF, microphthalmia-associated transcription factor; NF- $\kappa \mathrm{B}$, nuclear factor- $\kappa \mathrm{B}$; OLETF, Otsuka Long-Evans Tokushima fatty; OPG, osteoprotegerin; RANK, receptor for activation of nuclear

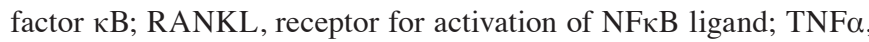
tumor necrosis factor $\alpha$; TRAP, tartrate resistant acid phosphatase

Key words: bone resorption, osteoclastogenesis, c-fms, obese rodent model, OLETF rats with the control group. These results suggested that hyperphagia-induced obesity with normal glycemic control induces the upregulation of osteoclastogenesis that is associated with an increase in the expression of c-fms, RANK and RANKL, which is induced by TNFo, via the activation of NFKB.

\section{Introduction}

Obesity is a state of excess storage of body fat, and is generally considered to be beneficial to bone health. However, recent data from epidemiological $(1,2)$ and animal studies (3-5) strongly suggest that fat accumulation may, in fact, be detrimental to bone mass.

In a high-fat diet-induced obese mouse model, the trabecular bone volume and trabecular number in the proximal tibia were shown to be decreased (3). A lower trabecular bone volume has been reported to be primarily the result of increased osteoclast resorption, as indicated by serum biomarkers and histomorphometry $(3,6-8)$. Osteoclastogenesis was reported to be enhanced in bone marrow-derived macrophages from obese mice (5). Although bone formation markers increased in cultured BMSCs in diet-induced obese mice (3), lower levels of distal femur cancellous bone mineral density and bone formation were also reported (8). The obese model mice used in these studies were fed a high-fat diet. A high-fat diet may interfere with intestinal calcium absorption (9) or serum lipid profiles (10), suggesting possible effects of diet on the bone metabolism of high-fat diet-induced obese mice. Thus, at present, the effects of obesity on bone resorption and bone formation remain unresolved, and the mechanisms underlying the effects of obesity on bone metabolism have not been fully elucidated.

The Otsuka Long-Evans Tokushima fatty (OLETF) rat lacks the cholecystokinin-1 (CCK1) receptor, due to a spontaneous genetic mutation, and represents a broadly established model of non-insulin-dependent diabetes mellitus $(11,12)$ and hyperphagia-induced obesity (13). CCK is a brain-gut peptide that acts as a peripheral satiety sequence (14). The development of obesity in this strain is secondary to hyperphagia (13). The OLETF rat obesity profile exhibits a number of features found in human obesity (15). Chronic overeating induces OLETF rats to become obese, and, unlike other rodent obesity models, male OLETF rats develop type II diabetes as they become obese (11), which may be normalized using food 
restriction (16), making them a particularly relevant model to the study of human obesity. The development of obesity in this strain begins very early in life, as a result of life-long abnormalities in eating behavior (15). OLETF rats display normal glycemic control at a young age (17-19), insulin resistance at 13 and 20 weeks, and develop overt type 2 diabetes by 40 weeks of age (20). After 24 weeks of age, these rats also exhibit impaired glucose tolerance (IGT), associated with a marked increase in plasma insulin (18), and have also been reported to display an increase in bone alkaline phosphatase (ALP) and tartrate-resistant acid phosphatase (TRAP) activities in serum, in addition to a decrease in bone mineral density, associated with hyperglycemia and obesity (21). However, it is not known which of obesity or hyperglycemia/insulin resistance is responsible for these changes in bone metabolism.

The present study investigated the effects of obesity on bone metabolism and the gene expression involved in osteoclastogenesis in vivo, using an animal model of obesity, the OLETF rat, which exhibits normal glycemic control at 8 weeks of age.

\section{Materials and methods}

Animals and diets. OLETF rats or their wild-type counterparts, Long-Evans Tokushima Otsuka (LETO) male rats (4 weeks old, 20 rats for each group), were obtained from Japan SLC (Shizuoka, Japan) and housed individually in a temperature-controlled room with a 12-h light/dark cycle. The LETO and OLETF rats were fed American Institute of Nutrition (AIN)-76A (Research Diets, Inc., New Brunswick, NJ, USA). In order to examine glycemic control in OLETF rats, the fasting serum levels of glucose and insulin (sampled from the tail vein) were determined following $16 \mathrm{~h}$ fasting at 8, 16 and 24 weeks of age. At 8 weeks of age, the blood, abdominal fat (omental and retroperitoneal), femoral and tibial bone, and bone marrow cells were collected under anesthesia using sodium pentobarbital (Kyoritsuseiyaku, Tokyo, Japan) following overnight access to feed (non-fasting samples). Blood samples were used to determine the serum concentrations of osteocalcin, c-terminal crosslinking telopeptide (CTx), tumor necrosis factor $\alpha(\mathrm{TNF} \alpha)$ and interleukin-6 (IL-6). Following removal of muscle and tendons, the tibial bone was used for biochemical and histological analyses. Animal experiments were performed in accordance with protocols approved by the Animal Care Research Committee of Nara Women's University (Nara, Japan).

Biochemical analysis. Serum concentrations of glucose, insulin, osteocalcin, CTx, TNF $\alpha$ and IL- 6 were measured using the Glucose C-II-test Wako (Wako Diagnostics, Osaka, Japan), Ultra Sensitive Rat Insulin ELISA kit (Morinaga Institute of Biological Science, Tokyo, Japan), Rat osteocalcin ELISA DS kit (DS Pharma Biomedical Co., Ltd., Osaka, Japan), RatLaps EIA (Immunodiagnostic Systems Inc., Scottsdale, AZ, USA), Quantikine Rat TNF $\alpha$ immunoassay (R\&D Systems, Inc., Mineapolis, MN) and Quantikine Rat IL-6 immunoassay (R\&D Systems, Inc., Mineapolis, MN, USA), respectively.

The activities of ALP, TRAP and cathepsin K, and the quantities of $\mathrm{Ca}$ and hydroxyproline (Hyp) in the proximal tibia (the quarter from the aspect of the knee of the tibia) were determined as previously reported (22). Briefly, after homogenizing the proximal tibia with 10 volumes of $10 \mathrm{mM}$ triethanolamine buffer, $\mathrm{pH} 7.5$, stirring for $30 \mathrm{~min}$ and centrifugation at $12,000 \mathrm{x} \mathrm{g}$ for $20 \mathrm{~min}$ at $4^{\circ} \mathrm{C}$, an aliquot of the supernatant (the bone extracts) was used for determining the activities of ALP, TRAP, and cathepsin $\mathrm{K}$, and the insoluble pellets were used for determining the $\mathrm{Ca}$ and Hyp contents following hydrolysis with $6 \mathrm{~N} \mathrm{HCl}$ at $105^{\circ} \mathrm{C}$ for $24 \mathrm{~h}$. ALP and TRAP activities were determined using p-nitrophenyl phosphate (Nacalai Tesque, Inc., Kyoto, Japan) as the substrate, and one unit of activity is defined as the release of $1 \mathrm{nmol}$ p-nitrophenol per minute. The activity of cathepsin $\mathrm{K}$ was determined by a fluorogenic assay using the substrate Z-GPR-AMC (Enzo Biochem, Inc., New York, NY, USA) and the cathepsin B-specific inhibitor CA074 (Peptide Institute, Inc., Osaka, Japan) and one unit of activity was defined as 1 pmol of liberated 7-amino-4-methylcoumarin per minute. The amounts of $\mathrm{Ca}$ were determined by an o-cresolphthalein complexone method using commercial kits (Wako Diagnostic). The content of hydroxyproline was measured using the method of Bergman and Loxley (23).

Histological analysis. The tibia was fixed in $4 \%$ paraformaldehyde, decalcified in $10 \%$ EDTA, and embedded in paraffin (Nacalai Tesque, Inc.). Sections $(4 \mu \mathrm{m})$ were stained for TRAP activity using a leukocyte acid phosphatase kit (Sigma-Aldrich, St. Louis, MO, USA; 387-A), as previously described (24). Morphometric measurements of the trabecular structure (trabecular bone volume, bone surface, thickness and number), and the number of osteoblasts (cuboidal cells on trabecular surfaces) and osteoclasts (TRAP-stained cells with $\geq 3$ nuclei) were conducted at standardized sites (300x300 $\mu \mathrm{m})$ under the growth plate in the metaphysis of the proximal tibia with a digital camera (DP70; Olympus Corporation, Tokyo, Japan) attached to a light microscope (BX50; Olympus Corporation) according to the method of Parfitt et al (25).

Reverse transcription-quantitative polymerase chain reaction $(R T-q P C R)$. Total RNA from the proximal tibia was prepared using a commercial kit (Sepasol RNA I Super G, Nacalai Tesque Inc., Kyoto, Japan) following washing out of bone marrow cells and homogenization in the presence of $0.1 \mathrm{M}$ EDTA. Total RNA was reverse-transcribed using a first-strand cDNA synthesis kit (Toyobo Co., Ltd., Tokyo, Japan). qPCR was performed using the cDNA, or total RNA for the negative control, using Thunderbird SYBR qPCR mix (Toyobo Co., Ltd.) and specific primers (Life Technologies, Tokyo, Japan) using a Light Cycler real time PCR detection system (Toyobo Co., Ltd.). The sequences of the primers used were as follows: M-CSF forward, 5'-CATCCAGGCAGAGACTGACA-3' and reverse, 5'-TTCGCGCAGTGTAGATGAAC-3'; RANKL forward, 5'-AGCGCAGATGGATCCTAACA-3' and reverse, 5'-TCGAGTCCTGCAAACCTGTA-3'; OPG forward, 5'-GAG TGTGCGAATGTGAGGAA-3' and reverse, 5'-TGCTTTCGA TGACGTCTCAC-3'; c-fms: forward, 5'-TAGAGCCAGGTG CAACAGTG-3' and reverse, 5'-CGCATAGGGTCTTCAAG CTC-3'; PU.1: forward, 5'-TGGAGAAGCTGATGGCTTG-3' and reverse, 5'-CCTTGTGCTTGGACGAGAA-3'; microphthalmia-associated transcription factor (MITF) forward, 5'-TTGGAAGACATCCTGATGGAC-3' and reverse, 5'-GCT 
Table I. The serum levels of insulin and glucose at 8,16 , and 24 weeks of age.

\begin{tabular}{lllr}
\hline Age (weeks) & Fasting serum levels & LETO & OLETF \\
\hline 8 & Insulin $(\mathrm{ng} / \mathrm{ml})$ & $0.14 \pm 0.06$ & $0.13 \pm 0.02$ \\
& Glucose $(\mathrm{mg} / \mathrm{dl})$ & $64.2 \pm 5.42$ & $63.7 \pm 9.22$ \\
16 & Insulin $(\mathrm{ng} / \mathrm{ml})$ & $0.57 \pm 0.01$ & $0.71 \pm 0.09$ \\
& Glucose $(\mathrm{mg} / \mathrm{dl})$ & $75.0 \pm 1.25$ & $94.2 \pm 4.05^{\mathrm{a}}$ \\
24 & Insulin $(\mathrm{ng} / \mathrm{ml})$ & $0.58 \pm 0.01$ & $0.86 \pm 0.05^{\mathrm{a}}$ \\
& Glucose $(\mathrm{mg} / \mathrm{dl})$ & $83.2 \pm 2.32$ & $101.9 \pm 4.10^{\mathrm{a}}$ \\
\hline
\end{tabular}

Values are presented as the mean \pm standard error of the mean of 4 rats. ${ }^{a} \mathrm{P}<0.05$ compared with the corresponding LETO rat values. LETO, Long-Evans Tokushima Otsuka rats; OLETF, Otsuka Long-Evans Tokushima fatty rats.

GCTTGTTTTCGAAGCTC-3'; RANK forward, 5'-ATATGC CTGCATCCCCTGAA-3' and reverse, 5'-TAGCCATCCGT TGAGTTGGA-3'; TRAP forward, 5'-CAGCCTTATTACC GTTTGC-3' and reverse, 5'-GAATTGCCACACAGCAT CAC-3'; Cathepsin K forward, 5'- TGTCTGAGAACTATGG CTGTGG-3' and reverse, 5'-ATACGGGTAACGTCTTCA GAG-3'; actin forward, 5'-AGCCATGTACGTAGCCATCCA-3' and reverse, 5'-TCTCCGGAGTCCATCACAATG-3'. The amplification program consisted of 1 cycle for $1 \mathrm{~min}$ at $95^{\circ} \mathrm{C}$ followed by 45 cycles of $95^{\circ} \mathrm{C}$ for $15 \mathrm{sec}, 60^{\circ} \mathrm{C}$ for $15 \mathrm{sec}$, and $72^{\circ} \mathrm{C}$ for $30 \mathrm{sec}$. Melting curves were used to verify specific products. Levels of gene expression were determined relative to an internal standard (actin) using the $2^{-\Delta \Delta C t}$ method (26) and are expressed relative to the values of the LETO group.

Western blot analysis. Bone extracts from the proximal tibia, prepared as described (23), were used for the western blot analysis. The protein concentrations were measured using the BCA protein assay kit (Pierce of Thermo Fisher Scientific Inc., Rockford, IL, USA). Equal quantities of protein were separated using sodium dodecyl sulfate-polyacrylamide gel electrophoresis and transferred to membranes. Western blotting and reprobing were performed, and the chemiluminescent signals were quantified by a densitometer as previously reported (27). The rabbit polyclonal antibodies recognizing actin (sc-10731), M-CSF (sc-13103), RANKL (sc-9073), OPG (sc-11383), c-Fms (sc-13949), PU.1 (sc-22805), MITF (sc-25386), RANK (sc-9072), and p-NFkB p65 (Ser 276; sc-101749), the mouse monoclonal antibody of $\mathrm{NF}$ B $\mathrm{p} 65$ (sc-8008) and the goat anti-rabbit IgG-horseradish peroxidase (HRP; sc-2004) were purchased from Santa Cruz Biotechnology, Inc. (Santa Cruz, CA, USA). The goat anti-mouse $\operatorname{IgG}(\mathrm{H}+\mathrm{L})$ secondary antibody-HRP conjugate (62-6520) was purchased from Invitrogen Life Technologies (Carlsbad, CA, USA). The membranes were incubated with specific antibodies overnight at a 1:200 dilution at $4^{\circ} \mathrm{C}$ and then with the secondary antibody for $2 \mathrm{~h}$ at a 1:2,000 dilution at room temperature.

Analysis of clonogenic precursors of osteoclasts and in vitro colony formation assay. The minimal essential medium (MEM), bovine serum albumin (BSA), and methylcellulose were obtained from Sigma-Aldrich (St. Louis, MO, USA); penicillin, streptomycin, non-essential amino acid and sodium
Table II. Animal characteristics at 8 weeks of age.

\begin{tabular}{lcc}
\hline Characteristic & LETO & OLETF \\
\hline Body weight $(\mathrm{g})$ & & \\
Start & $64.1 \pm 1.5$ & $65.7 \pm 1.1$ \\
End & $241.7 \pm 4.6$ & $325.8 \pm 6.4^{\mathrm{a}}$ \\
Food intake (g/day) & $19.8 \pm 0.6$ & $33.0 \pm 0.6^{\mathrm{a}}$ \\
Fat mass $(\mathrm{g})$ & $3.16 \pm 0.24$ & $8.17 \pm 0.36^{\mathrm{a}}$ \\
Bone length (mm) & & \\
Femur & $30.6 \pm 0.1$ & $32.0 \pm 0.2^{\mathrm{a}}$ \\
Tibia & $35.0 \pm 0.3$ & $36.7 \pm 0.2^{\mathrm{a}}$ \\
Bone weight $(\mathrm{g})$ & & \\
Femur & $0.582 \pm 0.020$ & $0.748 \pm 0.010^{\mathrm{a}}$ \\
Tibia & $0.478 \pm 0.010$ & $0.606 \pm 0.010^{\mathrm{a}}$ \\
Proximal tibia & $0.206 \pm 0.010$ & $0.285 \pm 0.003^{\mathrm{a}}$ \\
\hline
\end{tabular}

Values are presented as the mean \pm standard error of the mean of 8 rats. ${ }^{\mathrm{a}} \mathrm{P}<0.05$ compared with the LETO rat group. LETO, Long-Evans Tokushima Otsuka rats; OLETF, Otsuka Long-Evans Tokushima fatty rats.

Table III. Bone biochemical markers.

\begin{tabular}{lcc}
\hline Marker & LETO & OLETF \\
\hline Proximal tibia & & \\
ALP activity (U/g) & $23.54 \pm 0.98$ & $22.57 \pm 0.56$ \\
TRAP activity (U/g) & $1.31 \pm 0.11$ & $1.63 \pm 0.05^{\mathrm{a}}$ \\
Cathepsin K activity (U/g) & $344.3 \pm 17.8$ & $730.8 \pm 35.3^{\mathrm{a}}$ \\
Ca $(\mathrm{mg} / \mathrm{g})$ & $96.8 \pm 1.6$ & $86.6 \pm 3.4^{\mathrm{a}}$ \\
Hyp $(\mu \mathrm{mol} / \mathrm{g})$ & $85.7 \pm 2.4$ & $79.6 \pm 3.0^{\mathrm{a}}$ \\
Serum & & \\
Osteocalcin $(\mathrm{ng} / \mathrm{ml})$ & $180.2 \pm 3.7$ & $171.1 \pm 4.5$ \\
CTx $(\mathrm{ng} / \mathrm{ml})$ & $21.8 \pm 0.3$ & $26.8 \pm 0.8^{\mathrm{a}}$ \\
\hline
\end{tabular}

Values are presented as the mean \pm standard error of the mean of 8 rats. ${ }^{a} \mathrm{P}<0.05$ compared with the LETO rat group. LETO, Long-Evans Tokushima Otsuka rats; OLETF, Otsuka Long-Evans Tokushima fatty rats; ALP, alkaline phosphatase; TRAP, tartrate-resistant acid phosphatase; hyp, hydroxyproline; CTx, C-terminal crosslinking telopeptide. 
Table IV. Bone histomorphometry.

\begin{tabular}{lcc}
\hline Morphometric measurement & LETO & OLETF \\
\hline Trabecular number $(/ \mathrm{mm})$ & $15.81 \pm 0.62$ & $15.86 \pm 0.38$ \\
Trabecular bone volume $(\%)$ & $57.21 \pm 2.42$ & $47.16 \pm 2.97^{\mathrm{a}}$ \\
Trabecular bone surface $\left(\mathrm{mm} / \mathrm{mm}^{2}\right)$ & $31.30 \pm 1.22$ & $31.40 \pm 0.75$ \\
Trabecular thickness $(\mu \mathrm{m})$ & $36.60 \pm 2.23$ & $30.09 \pm 2.55^{\mathrm{a}}$ \\
Osteoblast index & $28.1 \pm 1.2$ & $25.7 \pm 1.1$ \\
$(\mathrm{~N}$ Ob/mm trabecular bone length) & $3.7 \pm 0.4$ & $7.7 \pm 0.5^{\mathrm{a}}$ \\
Osteoclast index & & \\
$\quad$ N Oc/mm trabecular bone length) & & \\
\hline
\end{tabular}

Values are presented as the mean \pm standard error of the mean of 6 rats. ${ }^{a} \mathrm{P}<0.05$ compared with the LETO rat group. LETO, Long-Evans Tokushima Otsuka rats; OLETF, Otsuka Long-Evans Tokushima fatty rats; N, number; Ob, osteoblast; Oc, osteoclast.

Table V. Serum levels and mRNA levels in proximal tibia of TNF $\alpha$ and IL-6.

\begin{tabular}{lcc}
\hline Level & LETO & OLETF \\
\hline Serum levels $(\mathrm{pg} / \mathrm{ml})$ & & \\
TNF $\alpha$ & $14.98 \pm 0.50$ & $19.05 \pm 0.90^{\mathrm{a}}$ \\
IL-6 & $93.17 \pm 7.70$ & $91.25 \pm 10.00$ \\
mRNA levels & & \\
TNF $\alpha$ & $1.00 \pm 0.24$ & $1.79 \pm 0.22^{\mathrm{a}}$ \\
IL-6 & $1.00 \pm 0.17$ & $1.10 \pm 0.20$
\end{tabular}

Values are presented as the mean \pm standard error of the mean of 6 rats ${ }^{\mathrm{a}} \mathrm{P}<0.05$ compared with the LETO rat group. LETO, Long-Evans Tokushima Otsuka rats; OLETF, Otsuka Long-Evans Tokushima fatty rats; TNF $\alpha$, tumor necrosis factor $\alpha$; IL-6, interleukin-6.

pyruvate were purchased from Gibco Life Technologies (Carlsbad, CA, USA); and recombinant murine M-CSF and soluble RANKL were purchased from Peprotech (Rocky Hill, NJ, USA). Bone marrow cells were prepared from femurs and tibias of OLETF and LETO rats by flushing the bone marrow cavity with MEM containing penicillin (100 U/ml) and streptomycin $(100 \mu \mathrm{g} / \mathrm{ml})$.

The frequency of precursors of osteoclasts in bone marrow cells was assessed based on a limiting dilution assay (28) as previously described (29). Briefly, the bone marrow cells were seeded into 96-well plates at the density of 25, 50, 100, or 200 cells per well and cultured for 5 days in MEM containing penicillin $(100 \mathrm{U} / \mathrm{ml})$, streptomycin $(100 \mathrm{mg} / \mathrm{ml}), 10 \%$ fetal calf serum (FCS; Biological Industries, Kibbutz Beit Haemek, Israel), $1 \%$ non-essential amino acid, $1 \%$ sodium pyruvate, M-CSF ( $5 \mathrm{ng} / \mathrm{ml}$ ), and RANKL (5 ng/ml). The wells containing TRAP-positive multinucleated cells (MNCs) (3 or more nuclei/cell) were counted as osteoclast-positive after the TRAP staining using the leukocyte acid phosphatase kit (Sigma 387-A; Sigma-Aldrich). Plates with appropriate numbers of osteoclast-positive wells (6-20 of the 96 wells) from each experimental group were selected, and $1 /$ frequency of osteoclast precursors was calculated according

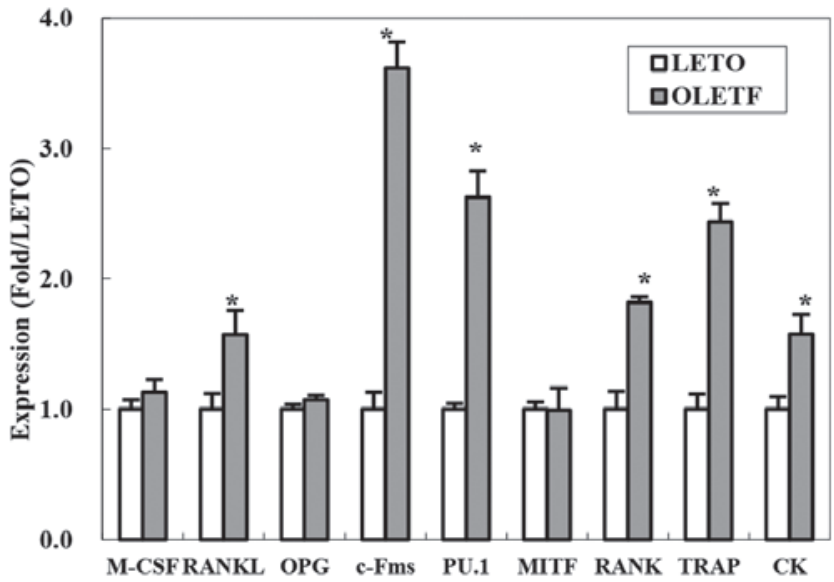

Figure 1. Expression of genes involved in osteoclastic differentiation in the proximal tibia. Total RNA was extracted from the proximal tibia of rats and the mRNA levels of M-CSF, RANKL, OPG, c-fms, PU.1, MITF, RANK, TRAP and CK were assessed by quantitative polymerase chain reaction, as described in the materials and methods section. Values are presented as the mean \pm standard error of the mean of 6 rats. Levels are expressed relative to that of the LETO rats (fold-increase). ${ }^{*} \mathrm{P}<0.05$, compared with the LETO rat group. M-CSF, macrophage colony-stimulating factor; RANKL, receptor for activation of nuclear factor- $\mathrm{B}$ ligand; OPG, osteoprotegerin; MITF, microphthalmia-associated transcription factor; TRAP, tartrate-resistant acid phosphatase; CK, cathepsin K; LETO, Long-Evans Tokushima Otsuka rats; OLETF, Otsuka Long-Evans Tokushima fatty rats.

to the following formula: $1 /$ frequency $=N /\{\ln [T /(T-P)]\}$, where $\mathrm{N}$ is the number of cells seeded in a well, $T$ is the number of wells per group, and $P$ is the number of osteoclast-positive wells.

The numbers of colony formation unit-macrophages (CFU-M) in bone marrow cells were determined as previously described (30). Briefly, bone marrow cells $\left(1 \times 10^{4}\right)$ were cultured in $1 \mathrm{ml}$ of MEM containing 1.2\% methylcellulose, 30\% FCS (Biological Industries), 1\% BSA and M-CSF (10 ng/ml) for 7 days, and the colonies were then counted.

Statistical analysis. Data are presented as the mean \pm standard error of the mean. All statistical analyses were performed by Welch's method using the Microsoft Excel Statistics analysis program 2012 (Social Survey Research Information Co. Ltd., 
A

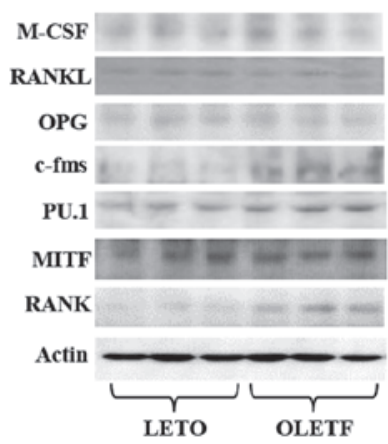

B

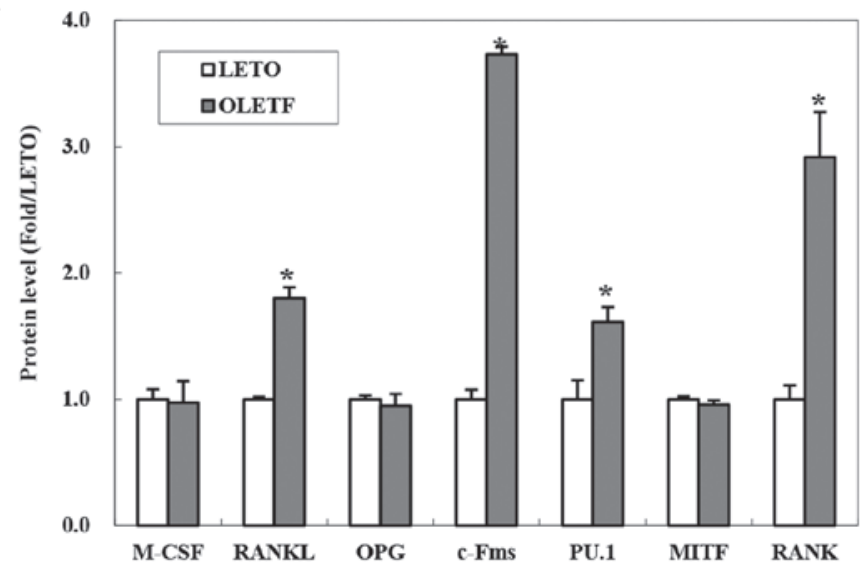

Figure 2. Protein levels of M-CSF, RANKL, OPG, c-fms, PU.1, MITF and RANK in the proximal tibia. Bone extracts from the proximal tibia of the rats were resolved by SDS-PAGE. Following transfer, the blot was probed or reprobed with antibody and detected by enhanced chemiluminescence, as described in the materials and methods section. (A) Western blot analyses. (B) Protein levels were quantified by densitometry and represented graphically. Data are presented as the mean \pm standard error of the mean of 6 rats. ${ }^{*} \mathrm{P}<0.05$, compared with the LETO rat group. M-CSF, macrophage colony-stimulating factor; RANKL, receptor for activation of nuclear factor- $\kappa \mathrm{B}$ ligand; OPG, osteoprotegerin; MITF, microphthalmia-associated transcription factor; LETO, Long-Evans Tokushima Otsuka rats; OLETF, Otsuka Long-Evans Tokushima fatty rats.

Tokyo, Japan). $\mathrm{P}<0.05$ was considered to indicate a statistically significant difference.

\section{Results}

Clinical characteristics and bone biochemical markers. The fasting serum levels of insulin and glucose of OLETF rats were similar to those of LETO rats at 8 weeks of age. However, glucose levels were significantly higher in OLETF rats at 16 and 24 weeks, and insulin levels were higher in this group at 24 weeks of age (Table I).

Body weight, food intake, fat mass, and length and weight of the femur and tibia were significantly higher in the OLETF than the LETO rats at 8 weeks old (Table II). The activities of TRAP and cathepsin $\mathrm{K}$ in the proximal tibia, and levels of serum CTx, significantly increased in OLETF rats compared with the LETO rats (Table III). However, ALP activity and serum osteocalcin levels were similar in the two groups (Table III). The levels of Ca and Hyp in OLETF rats significantly decreased, to $\sim 90 \%$ of that of the LETO rats.

Histological analysis. Morphometric measurements demonstrated that trabecular bone volume and thickness were lower in OLETF than LETO rats, although the trabecular bone surface and trabecular numbers were similar. The number of osteoclasts in the OLETF rats increased to 2.1-fold that of the LETO rats, while the numbers of osteoblasts were similar in the two groups (Table IV).

Expression of genes involved in osteoclastic differentiation in the proximal tibia. The gene expression levels of the osteoclastogenesis-related factors, M-CSF, RANKL, OPG, c-fms, PU.1, MITF and RANK, and the osteoclast-specific proteins, TRAP and cathepsin $\mathrm{K}$, relative to those of the internal control, actin, are shown in Fig. 1. The mRNA levels of RANKL, c-fms, PU.1 and RANK in OLETF rats were $1.6-, 3.6-, 2$.6- and 1.8-fold that of the LETO rats, respectively. However, no significant differences were observed in the mRNA levels of M-CSF,
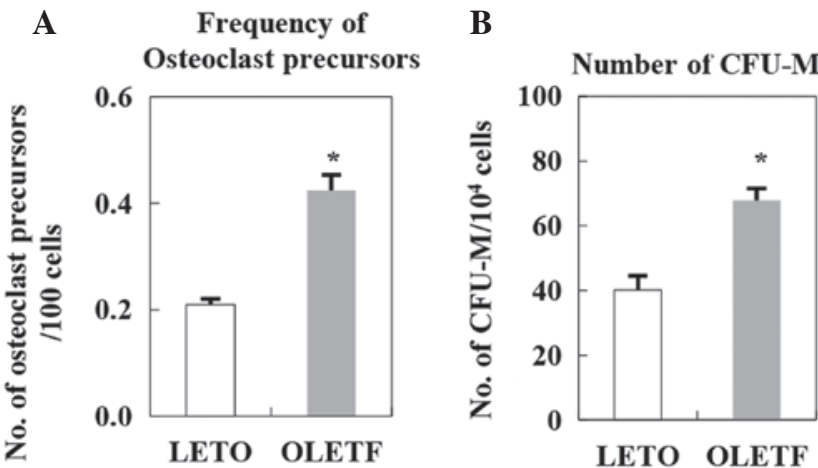

Figure 3. Population of osteoclast precursors and CFU-M in bone marrow cells. A frequency analysis of clonogenic osteoclast precursors in bone marrow cells (A) and an in vitro colony formation assay (B) were performed as described in the materials and methods section. Data are presented as the mean \pm standard error of the mean of 6 rats. ${ }^{*} \mathrm{P}<0.05$, compared with the LETO rat group. CFU-M, colony formation unit-macrophages; LETO, Long-Evans Tokushima Otsuka rats; OLETF, Otsuka Long-Evans Tokushima fatty rats.

OPG or MITF. The expression of TRAP and cathepsin K mRNA also increased to 2.4-and 1.4-fold that of the LETO rats, respectively.

Protein levels of M-CSF, RANKL, OPG, c-Fms, PU.1, $M I T F$ and RANK in the proximal tibia. The results of the western blot analysis are shown in Fig. 2. The protein levels of RANKL, c-Fms, PU.1 and RANK in the OLETF rat group were $\sim 1.8-, 3.7-, 1.6$ - and 2.9-fold that of the LETO rats, respectively, while the levels of M-CSF, OPG and MITF were unchanged (Fig. 2).

Pool of osteoclast precursors and CFU-M in bone marrow. The frequency analysis demonstrated that the population of osteoclast precursor cells in the bone marrow (frequency) was 0.21 and $0.42 \%$ in the LETO and OLETF rats, respectively, as shown in Fig. 3A. A colony assay showed that the number 
A

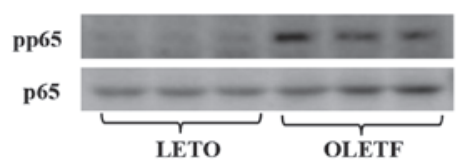

B

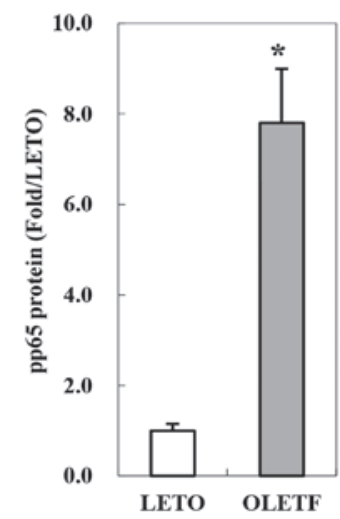

Figure 4. Activation of $\mathrm{NF \kappa B}$ in the proximal tibia. (A) Western blot analyses. Bone extracts from the proximal tibia of rats were resolved by SDS-PAGE. Following transfer, the blot was probed or reprobed with pp65 (Ser 276) or p65, and detected by enhanced chemiluminescence as described in the materials and methods section. (B) The protein levels were quantified by densitometry and represented graphically. Data are presented as the mean \pm standard error of the mean of 6 rats. ${ }^{*} \mathrm{P}<0.05$ compared with the LETO rat group. LETO, Long-Evans Tokushima Otsuka rats; OLETF, Otsuka Long-Evans Tokushima fatty rats; $\mathrm{NF \kappa B}$, nuclear factor-кB.

of colony-forming cells induced by M-CSF (CFU-M) in OLETF rats was also elevated to 1.7-fold that of the LETO rats (Fig. 3B).

Serum concentrations and proximal tibial $m R N A$ levels of $T N F \alpha$ and $I L-6$, and levels of activated $N F \kappa B$. The serum concentrations and mRNA levels of TNF $\alpha$ in the OLETF rats were $\sim 1.3$-and 1.8 -fold that of the LETO rats, respectively (Table V). However, no significant differences were observed in levels of IL-6 (Table V). The phosphorylation of NFKBp65 (pp65) is required for NFkB transcriptional activity. The pp65 protein in the OLETF group increased to $\sim 7.5$-fold that of the LETO rats (Fig. 4).

\section{Discussion}

The present study clearly demonstrated that obesity increased bone resorption in OLETF rats at 8 weeks of age. At this age, glycemic control was confirmed to be normal. The development of insulin resistance was observed at 24 weeks of age in OLETF rats in accordance with previous studies $(12,19)$. Under normal insulin and glycemic conditions, increases in body weight and fat mass substantially increased osteoclastic activity, and decreased $\mathrm{Ca}$ and Hyp levels in the proximal tibia of OLETF rats, although no significant change in osteoblastic activity was observed. The histological analysis showed that the increased osteoclastic activity was associated with an increase in the number of osteoclasts. No significant difference in the number of osteoblasts or bone formation markers was observed between OLETF and LETO rats, although decreased osteoblastogenesis and bone formation have been reported in high-fat diet-induced obese mice (8). These results suggested that hyperphagia-induced obesity with normal glycemic control, increased bone resorption, which was associated with an increase in osteoclastogenesis, while it did not affect osteoblastic activity in OLETF rats.

The precursors of osteoclasts are derived from hematopoietic stem cells in the bone marrow. However, their differentiation into osteoclasts occurs on the bone surface in vivo $(31,32)$. Therefore, the expression of osteoclastogenesis-related factors was examined in the bone. The mRNA and protein levels of RANKL, c-Fms and RANK were significantly higher in OLETF than in LETO rats, although no significant difference in M-CSF and OPG levels was observed between the two groups. M-CSF and RANKL are essential factors for osteoclast formation. The biological availability of RANKL is known to be assessed by the ratio of RANKL to its decoy receptor OPG (33-35). The increase in the mRNA and protein levels of RANKL, without an alteration in the levels of OPG in the OLETF rats indicated an obesity-induced increase in the biological availability of RANKL. The binding of M-CSF to c-fms is known to induce the expression of the RANKL receptor, RANK, in osteoclast precursors (36). The gene expression of RANK is known to be regulated by the transcription factors, PU.1 and MITF (37), although PU.1 is also required for c-fms expression (38). The expression of PU.1, but not MITF, was shown to be higher in OLETF than in LETO rats. An increased expression of PU.1 may lead to an increase in c-fms, and subsequently in RANK expression, as observed in OLETF rats. In vitro colony assays also demonstrated a larger population of monocyte/macrophage/osteoclast precursors $\left(\mathrm{c}-\mathrm{fms}^{+}\right.$cells) in the bone marrow of OLETF than in that of LETO rats. Stimulation of osteoclast differentiation and bone resorption has also been reported in bone marrow-derived macrophages from high-fat diet-induced obese mice (5). The current results, for the first time, showed that obesity increased the population of c-fms-positive precursors of osteoclasts in bone marrow cells and subsequently elevated osteoclast differentiation, leading to increased bone resorption in OLETF rats.

The expression of $\mathrm{c}-\mathrm{fms}$ has been shown to be induced by $\mathrm{TNF} \alpha(39)$. TNF $\alpha$ is also known to induce RANKL $(40,41)$. Obesity is associated with chronic inflammation, and increases in circulating and tissue pro-inflammatory cytokines, such as TNF $\alpha$ and IL6. Indeed, increased serum levels of TNF $\alpha$, although not of IL6, were observed in OLETF rats. In addition to the serum concentrations, the mRNA levels of TNF $\alpha$ in the proximal tibia of OLETF rats also increased, suggesting that it acts through an autocrine and/or paracrine mechanism. In high-fat diet-induced obese mice, serum levels and tibial bone mRNA of TNF $\alpha$ also increased (8). The elevated TNF $\alpha$ levels may result from the increased fat mass observed in OLETF rats. These results suggested that obesity increases the expression of c-fms and RANKL, via an increase in TNF $\alpha$ expression.

TNF $\alpha$ is induced by NFKB (42). The pivotal pro-inflammatory transcription factor, $\mathrm{NF \kappa B}$, is known to induce the expression of inflammatory mediators, such as $\mathrm{TNF} \alpha$ (42). In the present study, increased $\mathrm{NF} \kappa \mathrm{B}$ activation (determined by measuring $\mathrm{p}-\mathrm{NF} \mathrm{KB}, \mathrm{Pp} 65$ ) was observed in OLETF rats. These results suggested that the increase in TNF $\alpha$ is mediated through NFKB activation. 
In conclusion, the present study provides evidence that obesity increases osteoclastogenesis by upregulation of the expression of c-fms, RANK and RANKL, through NFkB-mediated expression of the inflammatory mediator, $\mathrm{TNF} \alpha$.

\section{References}

1. Hsu YH, Venners SA, Terwedow HA, et al: Relation of body composition, fat mass and serum lipids to osteoporotic fractures and bone mineral density in Chinese men and women. Am J Clin Nutr 83: 146-154, 2006.

2. Zhao LJ, Jiang H, Papasian CJ, et al: Correlation of obesity and osteoporosis: Effect of fat mass on the determination of osteoporosis. J Bone Miner Res 23: 17-29, 2008.

3. Cao JJ, Gregoire BR and Gao H: High-fat diet decreases cancellous bone mass but has no effect on cortical bone mass in the tibia in mice. Bone 44: 1097-1104, 2009.

4. Fehrendt H, Linn T, Hartmann S, et al: Negative influence of a long-term high-fat diet on murine bone architecture. Int $\mathrm{J}$ Endocrinol 2014: 318924, 2014.

5. Kyung TW, Lee JE, Phan TV, Yu R and Choi HS: Osteoclastogenesis by bone marrow-derived macrophages is enhanced in obese mice. J Nutr 139: 502-506, 2009.

6. Halade GV, Rahman MM, Williams PJ and Fernandes G: High fat diet-induced animal model of age-associated obesity and osteoporosis. J Nutr Biochem 21: 1162-1169, 2010.

7. Patsch JM, Kiefer FW, Varga P, et al: Increased bone resorption and impaired bone microarchitecture in short-term and extended high-fat diet-induced obesity. Metabolism 60: 243-249, 2011.

8. Baek K, Hwang HR, Park HJ, et al: TNF- $\alpha$ upregulates sclerostin expression in obese mice fed a high-fat diet. J Cell Physiol 229: 640-650, 2014

9. Xiao Y, Cui J, Shi YH, Sun J, Wang ZP and Le GW: Effects of duodenal redox status on calcium absorption and related genes expression in high-fat diet-fed mice. Nutrition 26: 1188-1194, 2010.

10. Chen JR, Lazarenko OP, Wu X, et al: Obesity reduces bone density associated with activation of PPAR $\gamma$ and suppression of $\mathrm{Wnt} / \beta$-catenin in rapidly growing male rats. PLoS One 5: e13704, 2010.

11. Kawano K, Hirashima T, Mori S, Saitoh Y, Kurosumi M and Natori T: Spontaneous long-term hyperglycemic rat with diabetic complications. Otsuka Long-Evans Tokushima Fatty (OLETF) strain. Diabetes 41: 1422-1428, 1992.

12. Kawano K, Hirashima T, Mori S and Natori T: OLETF (Otsuka Long-Evans Tokushima Fatty) rat: A new NIDDM rat strain. Diabetes Res Clin Pract (Suppl 24): S317-S320, 1994.

13. Moran TH and Bi S: Hyperphagia and obesity of OLETF rats lacking CCK1 receptors: Developmental aspects. Dev Psychobiol 48: 360-367, 2006.

14. Gibbs J, Young RC and Smith GP: Cholecystokinin elicits satiety in rats with open gastric fistulas. Nature 245: 323-325, 1973.

15. Schroeder M, Zagoory-Sharon O, Shbiro L, et al: Development of obesity in the Otsuka Long-Evans Tokushima Fatty rat. Am J Physiol Regul Integr Comp Physiol 297: R1749-R1760, 2009.

16. Bi S, Ladenheim EE, Schwartz GJ and Moran TH: A role for NPY overexpression in the dorsomedial hypothalamus in hyperphagia and obesity of OLETF rats. Am J Physiol Regul Integr Comp Physiol 281: R254-R260, 2001.

17. Man ZW, Hirashima T, Mori S and Kawano K: Decrease in triglyceride accumulation in tissues by restricted diet and improvement of diabetes in Otsuka Long-Evans Tokushima fatty rats, a non-insulin-dependent diabetes model. Metabolism 49: 108-114, 2000.

18. Park SY, Choi GH, Choi HI, Ryu J, Jung CY and Lee W: Calorie restriction improves whole-body glucose disposal and insulin resistance in association with the increased adipocyte-specific GLUT4 expression in Otsuka Long-Evans Tokushima fatty rats. Arch Biochem Biophys 436: 276-284, 2005.

19. Bajotto G, Murakami T, Nagasaki M, et al: Downregulation of the skeletal muscle pyruvate dehydrogenase complex in the Otsuka Long-Evans Tokushima Fatty rat both before and after the onset of diabetes mellitus. Life Sci 75: 2117-2130, 2004.

20. Laye MJ, Rector RS, Warner SO, et al: Changes in visceral adipose tissue mitochondrial content with type 2 diabetes and daily voluntary wheel running in OLETF rats. J Physiol 587: 3729-3739, 2009.
21. Omi N, Nakamura T and Ezawa I: Modulation of bone mass and turnover in growing rats by voluntary weight-bearing exercise and glucose supplementation. J Nutr Sci Vitaminol (Tokyo) 44: 409-421, 1998

22. Hie M, Shimono M, Fujii K and Tsukamoto I: Increased cathepsin $\mathrm{K}$ and tartrate-resistant acid phosphatase expression in bone of streptozotocin-induced diabetic rats. Bone 41: 1045-1050, 2007.

23. Bergman I and Loxley R: The determination of hydroxyproline in urine hydrolysates. Clin Chim Acta 27: 347-349, 1970.

24. Goto A and Tsukamoto I: Increase in tartrate-resistant acid phosphatase of bone at the early stage of ascorbic acid deficiency in the ascorbate-requiring Osteogenic Disorder Shionogi (ODS) rat. Calcif Tissue Int 73: 180-185, 2003.

25. Parfitt AM, Drezner MK, Glorieux FH, et al: Bone histomorphometry: Standardization of nomenclature, symbols and units. Report of the ASBMR Histomorphometry Nomenclature Committee. J Bone Miner Res 2: 595-610, 1987.

26. Livak KJ and Schmittgen TD: Analysis of relative gene expression data using real-time quantitative PCR and the 2(-Delta Delta C(T)) Method. Methods 25: 402-408, 2001.

27. Hie M, Yamazaki M and Tsukamoto I: Curcumin suppresses increased bone resorption by inhibiting osteoclastogenesis in rats with streptozotocin-induced diabetes. Eur J Pharmacol 621: $1-9,2009$.

28. Sato T, Shibata T, Ikeda K and Watanabe K: Generation of bone-resorbing osteoclasts from B220+ cells: its role in accelerated osteoclastogenesis due to estrogen deficiency. J Bone Miner Res 16: 2215-2221, 2001

29. Hie M, Iitsuka N, Otsuka T, Nakanishi A and Tsukamoto I: Zinc deficiency decreases osteoblasts and osteoclasts associated with the reduced expression of Runx 2 and RANK. Bone 49: 1152-1159, 2011.

30. Hie $\mathrm{M}$ and Tsukamoto I: Increased expression of the receptor for activation of NF- $\kappa \mathrm{B}$ and decreased runt-related transcription factor 2 expression in bone of rats with streptozotocin-induced diabetes. Int J Mol Med 26: 611-618, 2010.

31. Hayashi S, Miyamoto A, Yamane T, et al: Osteoclast precursors in bone marrow and peritoneal cavity. J Cell Physiol 170: 241-247, 1997.

32. Manolagas SC: Birth and death of bone cells: Basic regulatory mechanisms and implications for the pathogenesis and treatment of osteoporosis. Endocr Rev 21: 115-137, 2000.

33. Suda T, Takahashi N, Udagawa N, Jimi E, Gillespie MT and Martin TJ: Modulation of osteoclast differentiation and function by the new members of the tumor necrosis factor receptor and ligand families. Endocr Rev 20: 345-357, 1999

34. Riggs BL: The mechanisms of estrogen regulation of bone resorption. J Clin Invest 106: 1203-1204, 2000.

35. Hofbauer LC, Khosla S, Dunstan CR, Lacey DL, Boyle WJ and Riggs BL: The roles of osteoprotegerin and osteoprotegerin ligand in the paracrine regulation of bone resorption. $\mathrm{J}$ Bone Miner Res 15: 2-12, 2000.

36. Arai F, Miyamoto T, Ohneda O, et al: Commitment and differentiation of osteoclast precursor cells by the sequential expression of c-Fms and receptor activator of nuclear factor kappaB (RANK) receptors. J Exp Med 190: 1741-1754, 1999.

37. Ishii J, Kitazawa R, Mori K, et al: Lipopolysaccharide suppresses RANK gene expression in macrophages by down-regulating PU.1 and MITF. J Cell Biochem 105: 896-904, 2008.

38. Zhang DE, Hetherington CJ, Chen HM and Tenen DG: The macrophage transcription factor PU.1 directs tissue-specific expression of the macrophage colony-stimulating factor receptor. Mol Cell Biol 14: 373-381, 1994.

39. Yao Z, Li P, Zhang Q, et al: Tumor necrosis factor-alpha increases circulating osteoclast precursor numbers by promoting their proliferation and differentiation in the bone marrow through up-regulation of c-Fms expression. J Biol Chem 281: 11846-11855, 2006.

40. Manolagas SC, Kousteni S and Jilka RL: Sex steroids and bone. Recent Prog Horm Res 57: 385-409, 2002.

41. Fujita D, Yamashita N, Iita S, Amano H, Yamada S and Sakamoto K: Prostaglandin E2 induced the differentiation of osteoclasts in mouse osteoblast-depleted bone marrow cells. Prostaglandins Leukot Essent Fatty Acids 68: 351-358, 2003.

42. Singer P, Shapiro H, Theilla M, Anbar R, Singer J and Cohen J: Anti-inflammatory properties of omega-3 fatty acids in critical illness: Novel mechanisms and an integrative perspective. Intensive Care Med 34: 1580-1592, 2008. 